\title{
Post-Injection Geophysical Evaluation of the Winding Ridge Site CRADA 98-F012, Final Report
}

\author{
Terry Ackman \\ Connie Lyons \\ Richard Current
}

September 16, 1998

U.S. Department of Energy

Federal Energy Technology Center

P.O. Box 10940

626 Cochrans Mill Road

Pittsburgh, PA 15236-0940

and

State of Maryland

Department of Natural Resources

Tawes State Office Bldg. B3

Annapolis, MD 21401 


\section{Disclaimer}

This report was prepared as an account of work sponsored by an agency of the United States Government. Neither the United States Government nor any agency thereof, nor any of their employees, makes any warranty, express or implied, or assumes any legal liability or responsibility for the accuracy, completeness, or usefulness of any information, apparatus, product, or process disclosed, or represents that its use would not infringe privately owned rights. Reference herein to any specific commercial product, process, or service by trade name, trademark, manufacturer, or otherwise does not necessarily constitute or imply its endorsement, recommendation, or favoring by the United States Government or any agency thereof. The views and opinions of authors expressed herein do not necessarily state or reflect those of the United States Government or any agency thereof. 


\section{DISCLAIMER}

Portions of this document may be illegible in electronic image products. Images are produced from the best available original document. 


\title{
POST-INJECTION GEOPHYSICAL EVALUATION OF THE WINDING RIDGE SITE
}

\author{
by Terry Ackman ${ }^{1}$, Connie Lyons ${ }^{2}$, and Richard Current ${ }^{3}$
}

\section{INTRODUCTION}

Acid mine drainage (AMD) from underground mines is a major environmental problem. The disposal of coal combustion by-products (CCB) is also a major national problem due to the large volumes produced annually and the economics associated with transportation and environmentally safe disposal. The concept of returning large volumes of the CCB to their point of origin, underground mines, and using the typically alkaline and pozzolanic attributes of the waste material for the remediation of AMD has been researched rather diligently during the past few years by various federal and state agencies and universities. As the result, the State of Maryland initiated a full-scale demonstration of this concept in a small, 5-acre, unmapped underground mine located near Friendsville, MD.

Through a cooperative agreement between the State of Maryland and the U.S. Department of Energy, several geophysical techniques were evaluated as potential tools for the post-injection evaluation of the underground mine site. Three non-intrusive geophysical surveys, two electromagnetic (EM) techniques and magnetometry, were conducted over the Frazee Mine, which is located on Winding Ridge near Friendsville, MD. The EM surveys were conducted to locate ground water in both mine void and overburden. The presence of magnetite, which is naturally inherent to CCB's due to the combustion process and essentially transparent in sedimentary rock, provided the reason for using magnetometry to locate the final resting place of the $100 \%$ CCB grout.

\section{BACKGROUND}

Unabated acid mine drainage (AMD) from abandoned underground and surface coal mines has caused severe environmental damage to surface and groundwater supplies in the four coal basins of Maryland. At the same time, storage of conventional coal combustion ash by-products (CCB) from utility power plants presents environmental, logistic, and economic problems to local utilities and independent power producers. Currently, some of the alkaline by-products are being used during reclamation of

${ }^{1}$ Mining Engineer, Federal Energy Technology Center, U.S. Department of Energy, Pittsburgh, PA.

${ }^{2}$ Energy Resources Officer, Research Planning and Development, Bureau of Mines, Maryland Department of the Environment, Frostburg, Md.

WV.

${ }^{3}$ Engineer, Federal Energy Technology Center, U.S. Department of Energy, Morgantown, 
Maryland's surface coal mines (e.g., top soiling additives, surface infiltration barriers and alkaline pit liners). These alkaline by-products may also be useful for the abatement of acid mine drainage in underground coal mines. The Winding Ridge Project was a cooperative effort among: the Maryland Department of the Environment, MD Department of Natural Resources, Maryland coal industry, U.S. Office of Surface Mining and the U.S. Department of Energy. This project was conducted to demonstrate, investigate, and document the potential benefits and impacts of abating acid mine drainage by injecting grout admixtures made of alkaline coal combustion byproducts into a small, isolated abandoned underground coal mine.

\section{The Winding Ridge Site}

The Winding Ridge site is located in Garrett County, about 3.5 miles southeast of the village of Friendsville, Maryland. The Frazee Mine was intermittently operated from 1930 to 1960 and mined 5 acres of the Upper Freeport seam of coal using the room and pillar method. The land surface above the mine openings is an open field, facilitating access to the mine voids. The mine openings are located on the south face of Winding Ridge, in a forested area with moderate to thick underbrush at the openings. No mine map was available, so the mine layout was approximated based on conversations with former mine workers and a series of exploratory boreholes drilled during the summer ( 36 holes) and fall ( 27 holes) of 1995, and an additional 17 holes before and during injection activities in October, 1996. All boreholes were drilled to depths commensurate with the top of the coal seam 70 to 100 feet below the top of Winding Ridge.

The mine consists of two separate, parallel, partially collapsed mine adits, interconnected by numerous crosscuts, that drain as a single source of acid mine drainage. Both adits are estimated to be about 16 feet wide and were mined into the hillside to extract coal from the Upper Freeport seam, which is approximately 3 feet thick. The mine overburden consists of sandstone and shale. The thickness of the overburden ranges up to approximately 100 feet and tapers to the mine openings. The mine pavement consists of a dense, low permeability clay and dips to the openings at an angle of $3^{\circ}$ to $7^{\circ}$. The total mine void is unknown; however, historical data reported removal of 7,135 tons of coal during the operation of the mine.

\section{Water Quality and Quantity}

Samples taken by the Maryland Bureau of Mines and the U.S. Bureau of Mines in 1994 and 1995 characterized the water quality of the mine drainage. Pre-injection flows were moderate, varying between 9 and 23 gallons per minute. The $\mathrm{pH}$ measured in the low 3.0 's and high levels of aluminum, iron, magnesium, and sulfate were typical of AMD in the Appalachian coal region. Five shallow (i.e., 80 to 100 feet deep) bedrock monitoring wells were installed to monitor the first water-bearing zone commensurate with the elevation of the Frazee Mine. In addition, a deep ( 322 feet deep) bedrock well was installed to monitor the regional ground water quality downgradient of the mine. The regional water table lies approximately 50 to 80 feet below the Frazee Mine, based 
on the data collected at the deep monitoring well.

\section{The Winding Ridge Ash Injection}

The project consisted of injecting 5,600 cubic yards of $100 \%$ coal combustion byproduct grout into the mine voids through selected boreholes. The grout consisted of 60 percent FBC by-product ( 3800 tons), 20 percent FGD by-product (1,200 tons), 20 percent Class $F$ flyash (1200 tons) and approximately 471,000 gallons of water. The grout formulation yielded 8 inches of spread using ASTM PS 28-95, and a unconfined compressive strength of $520 \mathrm{psi}$, as determined using ASTM 39-94. The grout was mixed on-site with a moisture content of $57 \%$ primarily using water from within the mine. The grout was pumped into the boreholes. Camera logging during injection indicated that the grout was capable of flowing at least 100 feet along the mine pavement.

In 1997, one year after grouting, solidified grout cores were collected from the grouted mine voids to verify and investigate the results of the grout formulation. The cores are cement-like after one year of curing inside the deep mine voids. These cores are currently being tested for chemical and physical characteristics. Fourteen months of biweekly testing of the effluent waters from the mine and quarterly testing of the monitoring wells indicates that the project has had a beneficial impact on the waters to date. Monthly monitoring of the site and biannual testing of the wells will continue for at least another year to fully determine the extent of the impact of the ash grout on the mine discharges.

\section{GEOPHYSICAL TECHNIQUES}

The non-intrusive geophysical techniques applied at the Winding Ridge or Frazee Mine site include terrain conductivity, very low frequency (VLF) and magnetometry. Terrain conductivity and VLF are electromagnetic techniques, and the gradiometry is a standard magnetometer technique, which focuses on local rather than regional magnetic anomalies. For the purposes of this paper, the gradiometer is defined as a differential magnetometer where the spacing between sensors is fixed and small with respect to the distance to the local magnetic source. Terrain conductivity was used to locate water in the mine void or entries. The VLF was used to identify water-filled fracture zones above the grout injected mine, and the gradiometer was used to locate the injected CCB grout.

\section{Electromagnetic (EM) Techniques}

There are a number of electromagnetic (EM) instruments suitable for groundwater studies $^{4}$ that are commercially available. Conventional very low frequency (VLF) and ground conductivity were selected for use at the Frazee Mine site. Both are inductive

${ }^{4}$ Ward, S.H., ed., 1990. Geotechnical and Environmental Geophysics, Vol. 1: Review and Tutorial, Society of Exploration Geophysicists, Tulsa, OK, pp.191-218. 
electromagnetic (EMI) survey methods, that are now widely used to map near-surface geology by mapping variations in the electrical conductivity of the ground. EM techniques have proven useful for various groundwater studies, including: (1) groundwater exploration, (2) mapping industrial groundwater contamination, (3) mapping general groundwater quality (i.e., salinity) and saline intrusion, and (4) mapping soil salinity for agricultural purposes ${ }^{6 .}$

The principles behind EMI are complex. EMI techniques use current flow induced in the subsurface material by a surface transmitter. In this study, the Geonics EM34 terrain conductivity meter ${ }^{5}$ and ABEM WADI VLF ${ }^{5}$ instruments were used. In the case of the EM34, the surface transmitter is built into the instrument. An alternating electric current produced by the instrument's transmitter coil generates current flow or an alternating magnetic field (primary field). In the case of the VLF, the signal is generated by military VLF transmitters that operate at a specific frequency that can be selected automatically by the instrument or manually by the operator. The primary electromagnetic field penetrates the ground surface and induces current flow, and thus generates a secondary magnetic field (secondary field), which is sensed by the receiver coil in the EM34 and the antenna of the VLF. Numerous references have been provided for the reader who requires more details of the geophysical equipment and procedures.

\section{Electromagnetic Terrain Conductivity}

The EM34 measures signal strength between a transmitter coil and a receiver coil, when both are carried above a conducting body (e.g., a water-filled mine void) (Figure 1). An alternating current is generated in the transmitter with a frequency range between a few hundred and a few thousand hertz. This current induces an alternating magnetic field, called the primary field, which propagates through the surrounding area. An alternating current flows through the conducting body as the result of the primary field. This ground current causes another alternating magnetic field, called the secondary field, which also propagates through the surrounding area. The primary and secondary fields make up the complete magnetic field around the receiver. An alternating current in the receiver coil is induced by the combined magnetic field. The receiver coil measures the current, and thus, determines the combined magnetic field ${ }^{6}$.

${ }^{5}$ The United States Government does not endorse these manufacturers.

${ }^{6}$ Robinson, E.S. and C. Coruh. Electromagnetic Surveying. Sec. in Basic Exploration Geophysics, John Wiley and Sons, New York, 1st ed., 1988, pp. 490-500. 

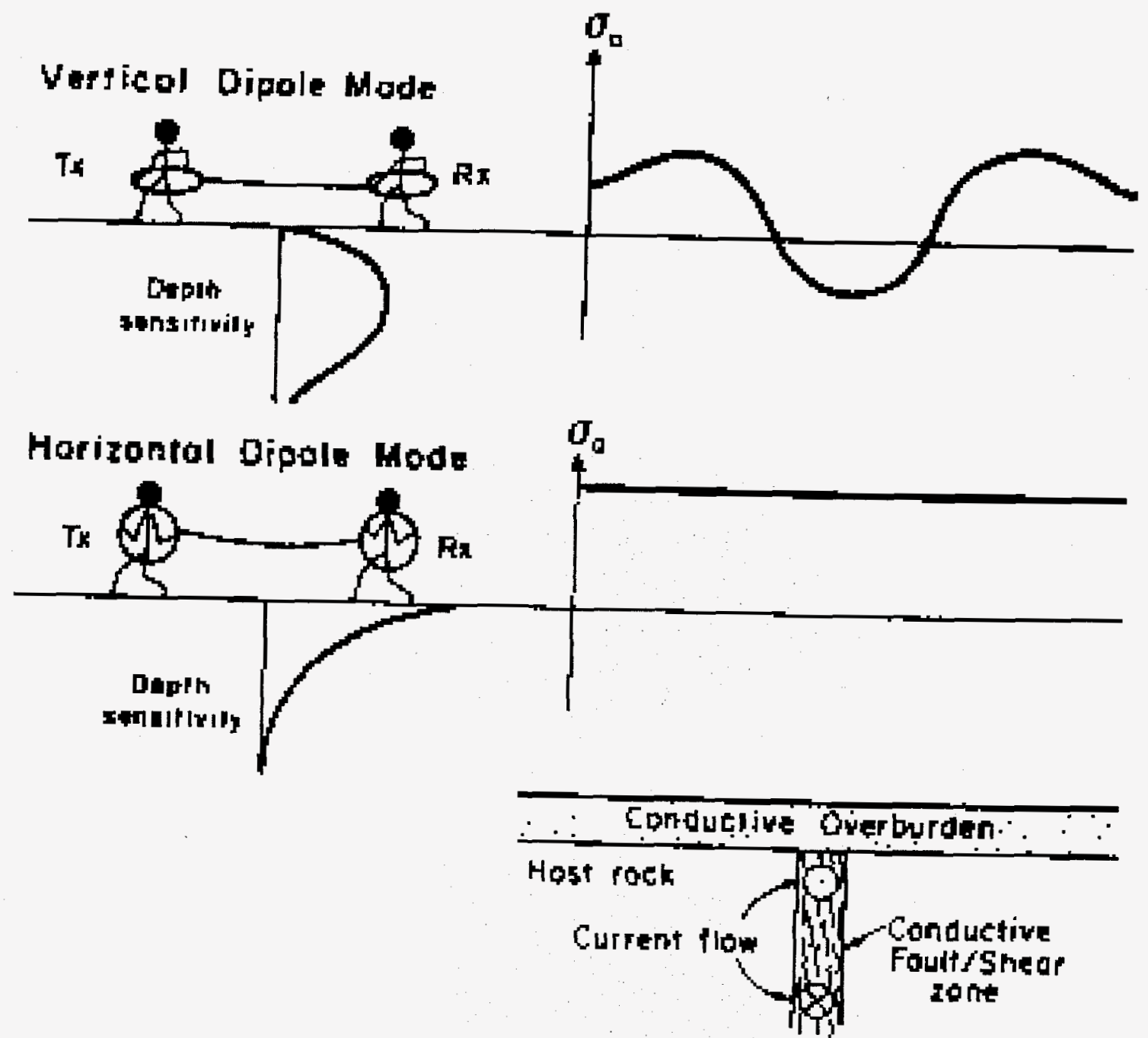

Figure 1. Schematic of EM34 operation

The EM34 generates readings of apparent conductivity ${ }^{7}$, which is expressed in millimhos per meter $(\mathrm{mmhos} / \mathrm{m})$. The apparent conductivity is calculated as follows:

$$
\sigma_{\mathrm{a}}=\left(4 / 2 \pi f \mu_{0} \mathbf{s}^{2}\right)\left(H_{s} / H_{p}\right)
$$

where $\sigma_{a}$ is the apparent ground conductivity, $H_{p}$ is the primary magnetic field, $H_{s}$ is the secondary magnetic field, $f$ is current frequency, $s$ is the distance between the transmitting and receiving coils, and $\mu_{0}$ is the permeability of free space ${ }^{7}$. The typical

${ }^{7}$ McNeill, J.D. Electromagnetic Terrain Conductivity Measurement at Low Induction Numbers. Technical Note TN-6, Geonics Limited, 1745 Meyerside Drive, Mississauga, Ontario, Canada, 1980a. 
practice is to compare the $H_{s}$ with a value $H_{p}$, which is the intensity of the primary field alone at some designated location. Since the coil positions and the current in the transmitter coil are known, the value of $H_{p}$ can be calculated ${ }^{6}$ The apparent conductivity (resistivity) is a composite of true conductivities (resistivities) for each geoelectric layer in the semi-infinite half-space below the ground surface. For the Geonics EM34, the depth of penetration as a function of the inter-coil separation and dipole orientation can be calculated by the method described by McNeill ${ }^{8,9}$.

Ground conductivity meters operate in both horizontal and vertical dipole modes. Each mode gives a significantly different response (sensitivity). The effective exploration depths for the two modes are approximately 0.75 (horizontal dipole) and 1.5 (vertical dipole) times the intercoil spacing in a layered earth geometry. Three different intercoil spacings are possible with the EM34: $10 \mathrm{~m}(33 \mathrm{ft}), 20 \mathrm{~m}(66 \mathrm{ft})$ and $40 \mathrm{~m}(131 \mathrm{ft})$. This spacing translates into the penetration depths shown in Table 1 . Finally, the basic components of the EM34 include: receiver console, transmitter console, receiver coil, transmitter coil, connecting cables and power supply.

\begin{tabular}{|c|c|c|}
\hline & \multicolumn{2}{|c|}{ Penetration Depth } \\
\hline $\begin{array}{c}\text { Intercoil } \\
\text { Spacing } \\
\text { meters (feet) }\end{array}$ & $\begin{array}{c}\text { Horizontal } \\
\text { Dipole }\end{array}$ & $\begin{array}{c}\text { Vertical } \\
\text { Dipole }\end{array}$ \\
\hline $10 \mathrm{~m}(33 \mathrm{ft})$ & $7.5 \mathrm{~m}(24.5 \mathrm{ft})$ & $15 \mathrm{~m}(49 \mathrm{ft})$ \\
\hline $20 \mathrm{~m}(66 \mathrm{ft})$ & $15 \mathrm{~m}(49 \mathrm{ft})$ & $30 \mathrm{~m}(98 \mathrm{ft})$ \\
\hline $40 \mathrm{~m}(131 \mathrm{ft})$ & $30 \mathrm{~m}(98 \mathrm{ft})$ & $60 \mathrm{~m}(197 \mathrm{ft})$ \\
\hline
\end{tabular}

\section{VERY LOW FREQUENCY}

Like most other EM methods, the VLF method can be used to find steeply dipping structures, such as vertical water-filled fractures, that differ from their surroundings with regard to electrical resistance ${ }^{10}$ The VLF method is very well suited for water prospecting in fracture zones and the physical principles of operation are similar to

${ }^{8}$ McNeill, J.D. EM34-3 Survey Interpretation Techniques. Technical Note TN-8, Geonics Limited, 1745 Meyersdale Drive, Mississauga, Ontario, Canada, $1980 \mathrm{~b}$.

${ }^{9}$ McNeill, J.D. Use of Electromagnetic Methods for Groundwater Studies. Ch in Geotechnical and Environmental Geophysics, ed. by S.H. Ward. Soc. of Expl. Geophys., P.O. Box 702740, Tulsa, OK, 74170-2740, pp. 194-198.

${ }^{10} \mathrm{ABEM}, \mathrm{ABEM}$ WADI VLF Instrument: Theory, practice and case stories for WADI operators. ABEM Printed Matter 93057, ABEM AB, Box 20086, S-16102 Bromma, Sweden, pp. 1-36, 1987. 
those described above for ground conductivity. The primary difference between ground conductivity and the VLF is that the EM34 instrument includes a transmitter and receiver, whereas the VLF instrument is simply a receiver. The low-frequency field that is sensed by the VLF instrument is sent out from military radio transmitters, which typically operate in a frequency between 15 and 30 kilohertz $(\mathrm{kHz})$. VLF transmitters are in operation at a number of sites throughout the world, including North America. A VLF transmitter consists of a vertical cable several hundred meters long that emits a very powerful (300-1000 kilowatt) transmission signal. The primary magnetic field emitted by the antenna is horizontal, and its magnetic lines are comprised of concentric rings that ripple out from the transmitter. When the field emitted by the military transmitter strikes a body having low electrical resisitivity (e.g., water-filled fractures), secondary currents are induced. This electrical phenomenon is the same thing that occurs in a bicycle-light generator when the rotating magnet induces currents in the coil. The secondary currents, in turn, create a secondary magnetic field that is opposed to the original field emitted by the transmitter ${ }^{10}$.

A recent study ${ }^{11}$ has shown that unless the earth is extremely resistive, the subsurface horizontal electric field, $E_{x}$, is responsible for virtually all VLF anomalies. When $E_{x}$

(Figure 2) is incident on a

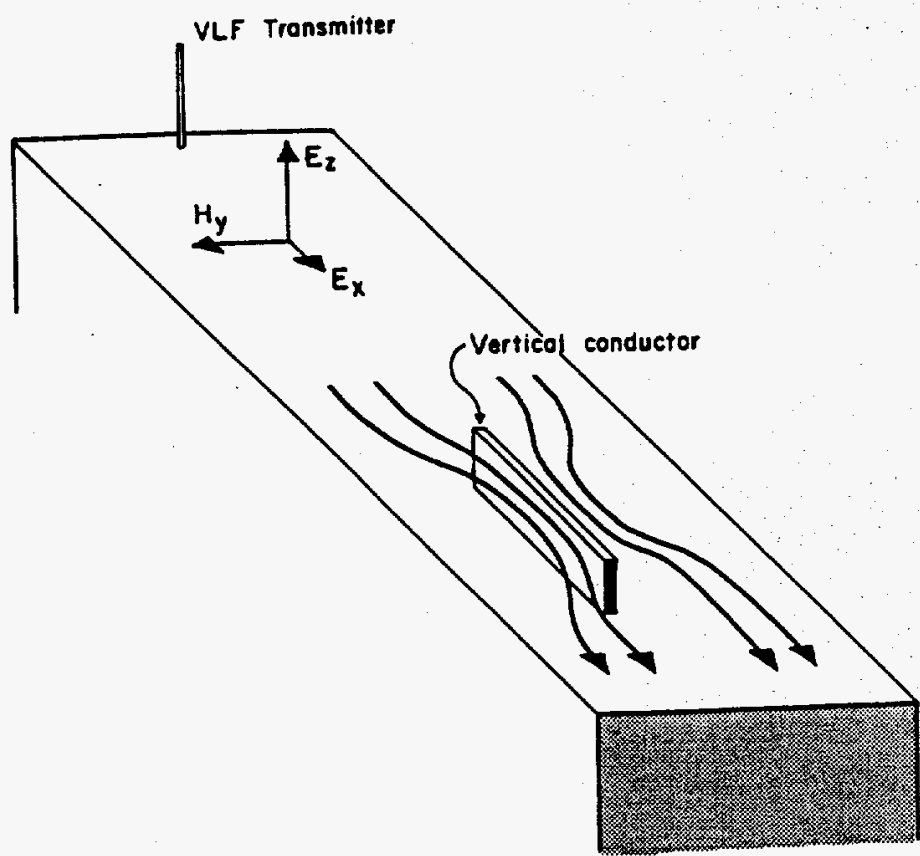

boundary between two materials of different resistivity, electric charges are induced at the interface and the secondary electric field is affected by these charges and modifies the original electric field. A "current channeling" effect results from the altered electric field and varying conductivity, which causes the currents to flow into subsurface bodies (e.g., water filled fractures) that are more conductive than the surrounding terrain, and away from the bodies that are more resistive?

Figure 2. Schematic of current channeling

${ }^{11}$ McNeill, J.D. and Labson, V., 1990, Geological mapping using VLF radio waves: in Nabighian, M.N., Ed., Electromagnetic methods in applied geophysics, Vol. 2, Soc. Expl. Geophys. (in press). 


\section{Magnetometry}

In magnetometry, various elements of the earth's magnetic field are measured, typically using a magnetometer. The earth's main magnetic field is approximately dipolar, and is perturbed by near surface rocks and material, which are magnetic to variable degrees. From these perturbations or anomalies in the expected magnetic field that are generated, we can deduce subsurface conditions. Since the field is a vector quantity, parameters we can measure include total field intensity, direction (declination and inclination) and field gradient. Gradient is obtained by measurement of the field at two locations, simultaneously, using two sensors separated a fixed distance. Contact with the ground is not necessary and both ground and aerial surveys can be completed. Magnetic surveying commonly consists of measuring total field intensity values at stations along a survey line or at an array of stations that cover an area. Total field data, which were not collected for this study, must be corrected for daily changes in the earth's magnetic field and, depending upon application, separation of anomalies due to different sources may be necessary. The data can be used to determine shallow subsurface conditions of $3 \mathrm{~m}$ (10 ft) or less, or deep crustal conditions. Data can be displayed as profiles or as contour maps. The information can be used qualitatively to determine where magnetic sources are located. Quantitative models can be derived to determine for dimensions, geometries, and depths of subsurface magnetic bodies. The magnetic surveying technique can be used to detect subsurface voids, map bedrock, map contacts between bodies of varying magnetic properties, map fracture zones, and locate metallic man-made objects such as well casings, drums, and pipelines. The advantages of the technique are that equipment is inexpensive and portable, large areas can be rapidly surveyed, and data processing is relatively simple. Disadvantages are that cultural interference can generate noise, and there can be non-unique solutions for a given data set.

\section{GEOPHYSICAL DATA}

There are three types of data presented in this report: (1) terrain conductivity, in millimhos per meter ( $\mathrm{mmhos} / \mathrm{m}$ ), (2) VLF, which is expressed as a percentage (\%) of vertical and horizontal fields at the ground surface, and (3) gradiometer measurements in gammas. All data have been plotted as contour maps. The VLF data were digitized from line plots due to manufacturer's software limitations. Data were collected by each instrument on an established grid that had 36 lines with varying numbers of stations per line. The stations, which were marked by wooden stakes, were evenly spaced at a distance of $10 \mathrm{~m}$ in both north/south and east/west directions. The dotted line shown in Figure A1 (see appendix A) outlines the 9.1 acre survey grid over the Frazee Mine.

This first effort took approximately 4 days to complete the 3 surveys over the site, which was all open field. The gently sloping site was, initially, slightly wet due to a precipitation event one day prior to starting work. There was no precipitation during the 4 days it took to complete the surveys. Multiple surveys were also completed simultaneously; however, operators were careful not to take readings unless the instruments were at least $70 \mathrm{~m}$ apart to prevent signal interferences. 


\section{FIELD PROCEDURES}

Terrain Conductivity - The EM34 survey was completed in an east/west direction and used a $40 \mathrm{~m}$ intercoil spacing, which was needed to reach a mine depth of approximately 70 to $100 \mathrm{ft}$. Two operators lined-up at survey stakes $40 \mathrm{~m}$ apart for each station reading (the reading was taken for the center stake). Two readings, horizontal and vertical dipoles, were taken at each station, which represented depths of $30 \mathrm{~m}(98 \mathrm{ft})$ and $60 \mathrm{~m}(197 \mathrm{ft})$. After each reading, the operators would advance $10 \mathrm{~m}$ in the same direction to the next set of stakes, while remaining 40 apart. The survey direction alternated direction with each survey line; however, the orientation of the transmitter (west) and receiver (east) remained constant throughout the survey.

Very Low Frequency (VLF) - The VLF survey was completed in a north/south direction. The instrument was turned to a frequency of $23.9 \mathrm{kHz}$, which is a military antenna located at Annapolis, MD. The strong, regionally dominant signal was optimized when the instrument operator and antenna were oriented in a north/south direction. Consequently, all readings were taken when the operator was facing either north or south. Readings were taken on $10 \mathrm{~m}$ intervals along a line and the survey direction alternated direction with each line.

Gradiometer- This survey, like the VLF's, was completed in a north/south direction. All metal objects on the site were either moved or noted. On this site, metal well casings, which were used for the monitoring wells (Figure 1A), and a piece of old farm equipment (metal) could not be removed from the path of the surveys. A base station, used for diurnal corrections on total (magnetic) field data, was not activated.

Consequently, only gradient data, which focuses on local anomalies, was collected.

\section{DATA ANALYSIS AND DISCUSSION}

Terrain Conductivity - A plot of the EM34 data for a $30 \mathrm{~m}$ depth is shown in Figure 2A. In all of the EM34 plots, the density of contour lines was increased to provide shading that would help delineate the flooded mine entries and solid coal pillars and the conductive (water or wet) zones. Based on the nearly $6,000 \mathrm{ft}^{3}$ injection of CCB grout, it was considered likely that pockets of water would develop in the mine after injection. Figure A2 displays contour lines that appear to produce several long, but interrupted lines of high conductivity that intersect at a perpendicular angle. Considering that the workings below were developed using a room-and-pillar mining technique and the shape and size of the apparent lines of high conductivity, these lines appear to indicate mine entries that contain water.

Figure $A 3$ is a plot of the conductivity data for the $60 \mathrm{~m}$ depth. Based on the vertical signal curves shown in Figure 1, the $60 \mathrm{~m}$ plot (Figure A3) has a better depth sensitivity than the $30 \mathrm{~m}$ depth (Figure A2). The lines of high conductivity appear to be better defined in the $60 \mathrm{~m}$ plot. The apparent reason for better resolution is that at the $30 \mathrm{~m}$ depth, or horizontal dipole mode, the average signal strength is oriented more to the 
near-surface. However, at the $60 \mathrm{~m}$ depth, or vertical dipole mode, the average signal strength is oriented more to the subsurface, thus providing a better sensitivity (or resolution) for a target (mine void) that is approximately $30 \mathrm{~m}$ deep.

Figures $A 2$ and $A 3$ were overlain, as shown in Figure $A 4$, to determine if the observed high conductivity trends at both depths, 30 and $60 \mathrm{~m}$, lined up in terms of trend, shape and size. As shown, it appears that there is good alignment between the depths, which is consistent with the wet or water-filled mine entries. However, without a pre-injection survey or a reasonably accurate mine map, it is not possible to determine definitely if the high conductivity zones are representative of existing, wet mine entries.

Very Low Frequency (VLF) - Figures A5 and A6 show contour maps of the VLF data at depths of $30 \mathrm{~m}$ and $60 \mathrm{~m}$, respectively. Although the VLF, like the EM34, is an electromagnetic technique, the fundamental difference in the two techniques must be considered when reviewing the plotted data. This difference is the signal source; the EM34 generates and transmits an electromagnetic field vertically from the surface down into the earth and the VLF instrument measures signals that are transmitted horizontally through the earth from far away locations. Due to this horizontal signal, the VLF instrument is able to identify water-filled fractures. Figures $A 5$ and $A 6$ show high ratio percentages in the north central and north eastern portions of both plots. Also, the deeper $60 \mathrm{~m}$ plots had overall higher values than the shallow plot. This observation suggests that there is a higher density of water-filled, vertical fractures in those portions of the site. Also, this observation suggests that these areas provide the most of the surface recharge to the mine pool and ground water table. These areas with the high values are most likely associated with gobbed or mined-out sections where the mine roof has collapsed across a large area and fracturing of the shallow overburden. This interpretation also suggests that this geophysical technique could also serve as a tool for identifying the location and extent of existing and potential subsidence zones.

It is also important to consider the dynamics of water flow in fracture systems when analyzing VLF data. Fracture flow is similar to sand in an hour glass, such that a fixed volume will drain over a fixed time period, unless it is replenished. The VLF signatures shown for depths of 30 and $60 \mathrm{~m}$ (Figures $\mathrm{A} 5$ and $\mathrm{A6}$ ) would be very different if the survey would have been conducted under drought conditions, rather than about $36 \mathrm{hrs}$ after a precipitation event. The lower overall data values of the shallow survey $(30 \mathrm{~m})$ reflect the fact that the upper fractures drain first, which reduces signal strength (data values).

Gradiometer - The gradient data is shown in Figure A7 and the darker and lighter shades of the contours represent the positive and negative portions of a magnetic anomaly. Also, the data has been filtered, such that the data presented includes only those gamma values within the range of -5 to +5 . This filtering was done to as a means to remove the extreme anomalies produced by steel monitoring wells. The original data ranged from a -50 gammas to about +600 gammas, which is extreme for an instrument that has a sensitivity of 0.5 gammas. A review of Figure A7 (and Figure A1) will show that the major anomalies are directly related to the steel cased monitoring wells (the 
clear areas within the anomaly produced by the data filtering have a monitoring well symbol and number). The use of steel well casings severely impaired our ability to observe the more subtle changes that would be expected from the magnetite in the CCB grout. However, the south central and south eastern portions of the site (Figure $7 \mathrm{~A}$ ), which were beyond the interference range of the steel cased wells and instrument, showed very promising results in that a number of more subtle anomalies can be observed. The problem is, that without a baseline survey, it cannot be stated with certainty that the observed anomalies were created by CCB grout injection.

\section{SUMMARY AND CONCLUSION}

The data presented in this paper indicate that a variety of non-intrusive geophysical techniques can be collectively used to conduct post-injection evaluations of remedial efforts. The terrain conductivity technique appeared to delineate the wet mine entries, which in the absence of mine maps, could be significant. The VLF technique appeared to locate water-filled fracture zones in the overburden, and also demonstrated the potential to locate existing or potential mine subsidence zones. The plotted gradiometer data, when not masked by the major anomalies produced by the steel cased wells, showed numerous and relatively subtle anomalies, that may have been associated with the CCB injection.

A pre-injection (baseline) survey is obviously very important to have. However, even without such a survey, the geophysical tools proved useful. Work could be done at the Frazee site or a new injection site to further develop these tools for practical applications. At the Frazee site additional camera and drilling work could be done to validate existing data. Alternatively, a new grout injection site would provide the opportunity to get a clear before and after site evaluation and allow for a more thorough interpretation of data. 
APPENDIX A 


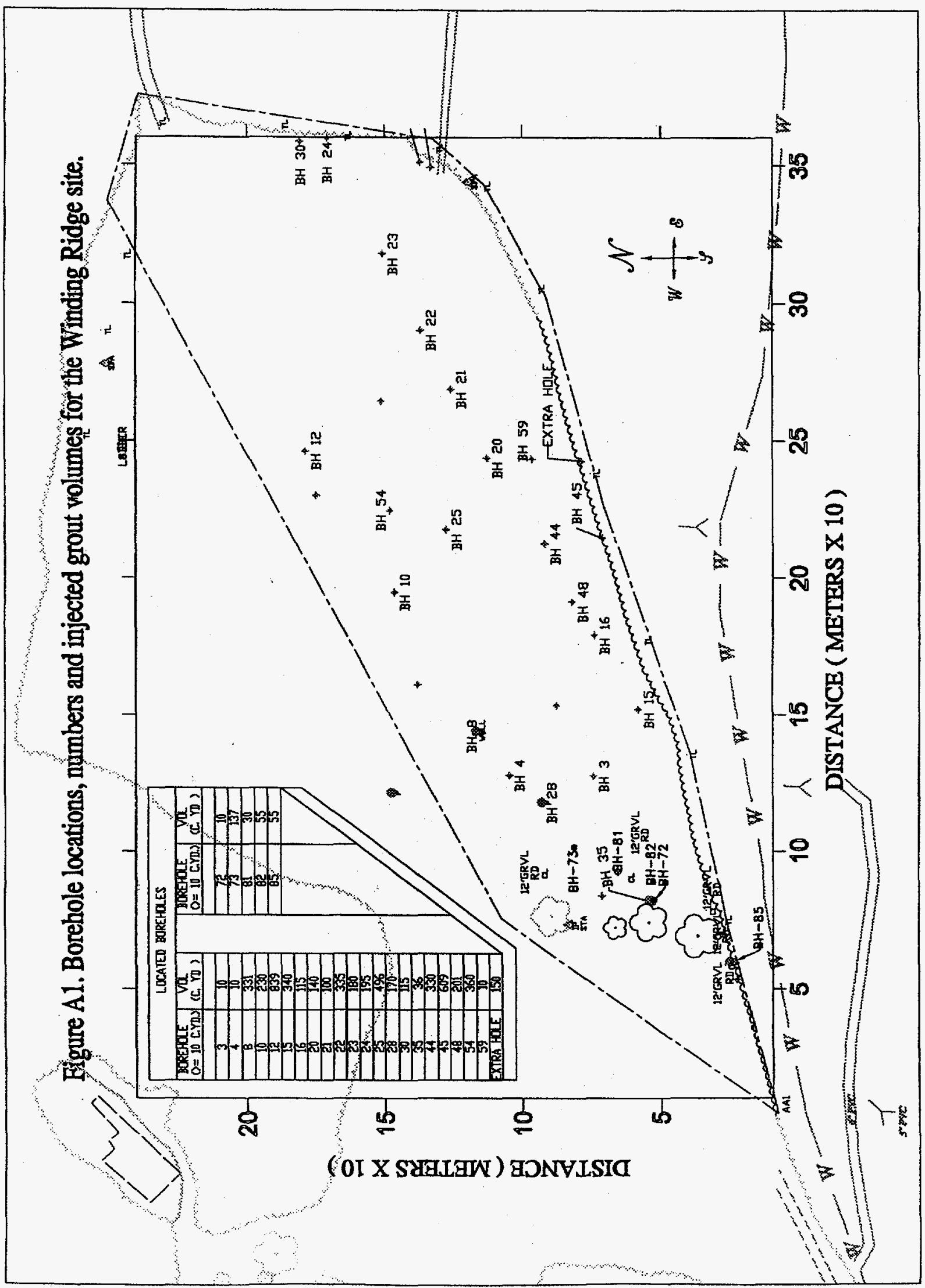




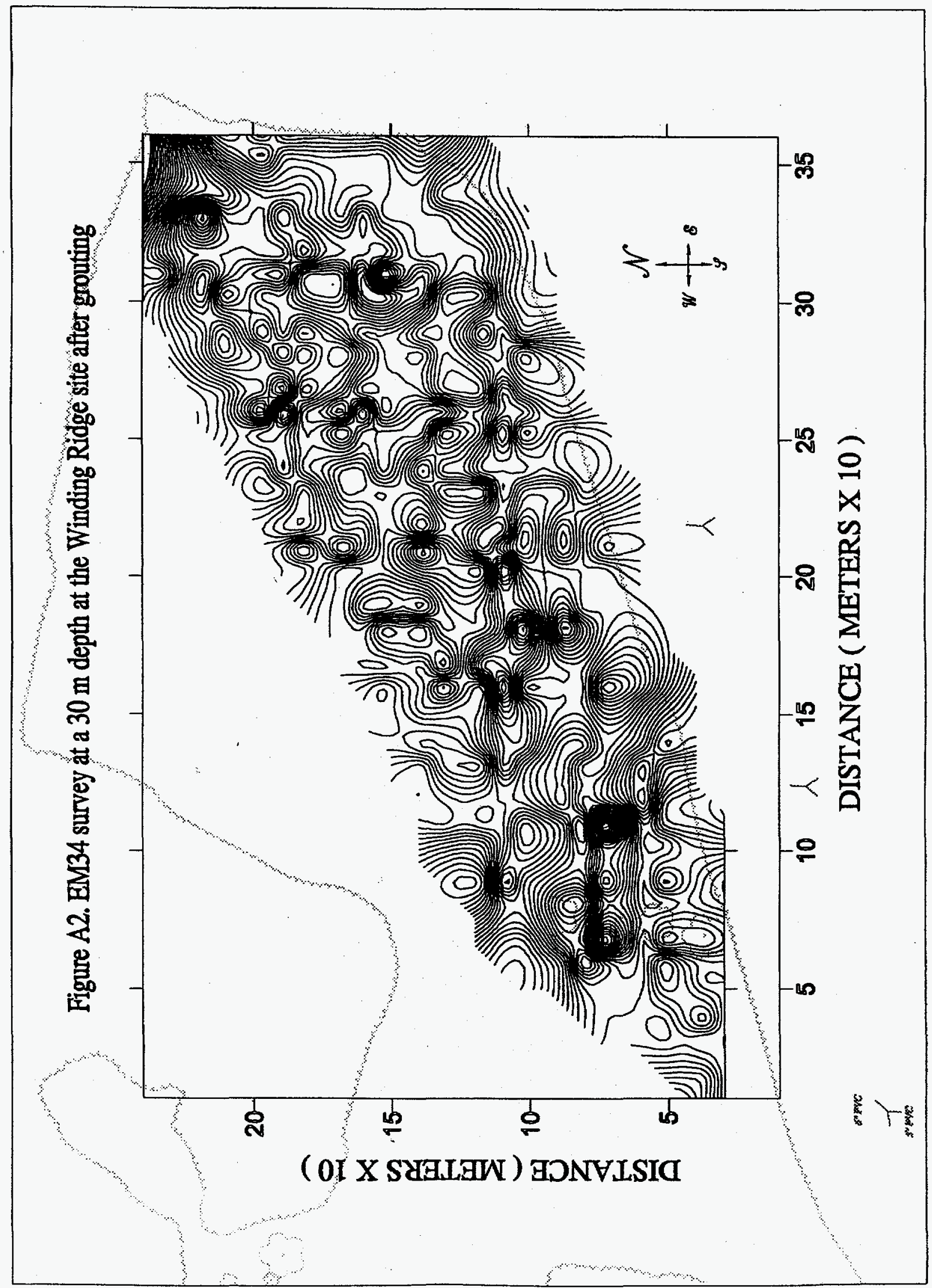




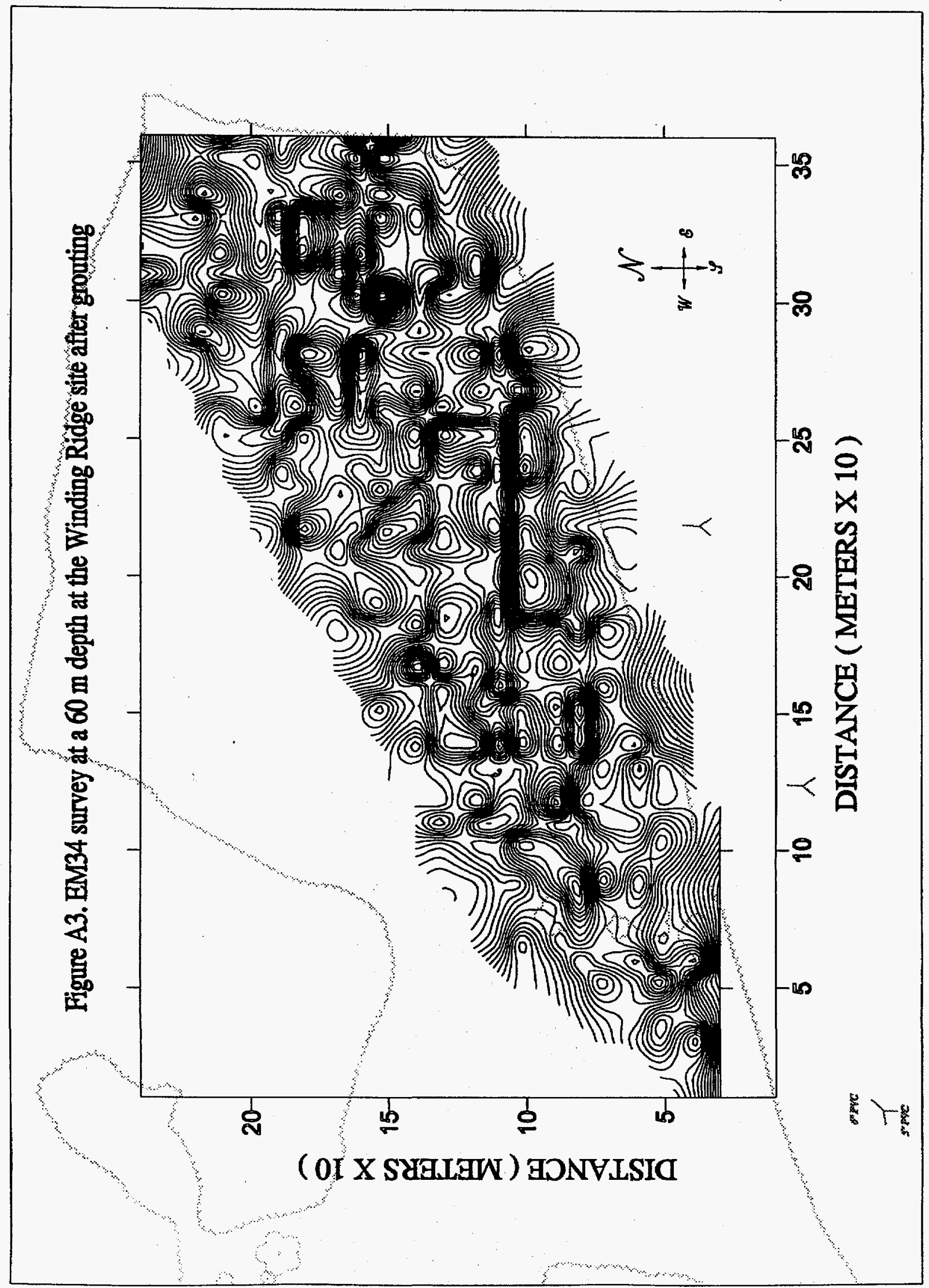




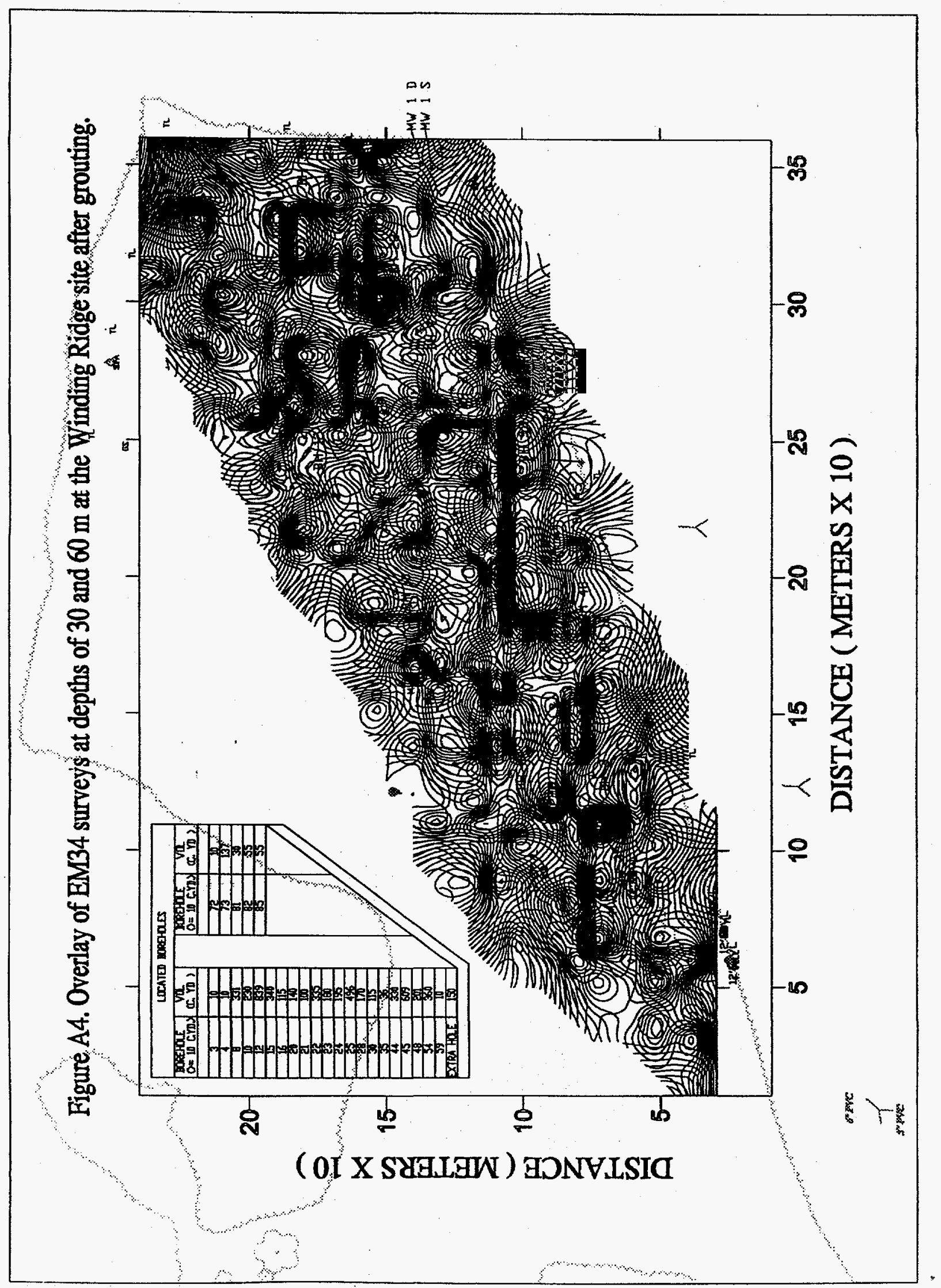




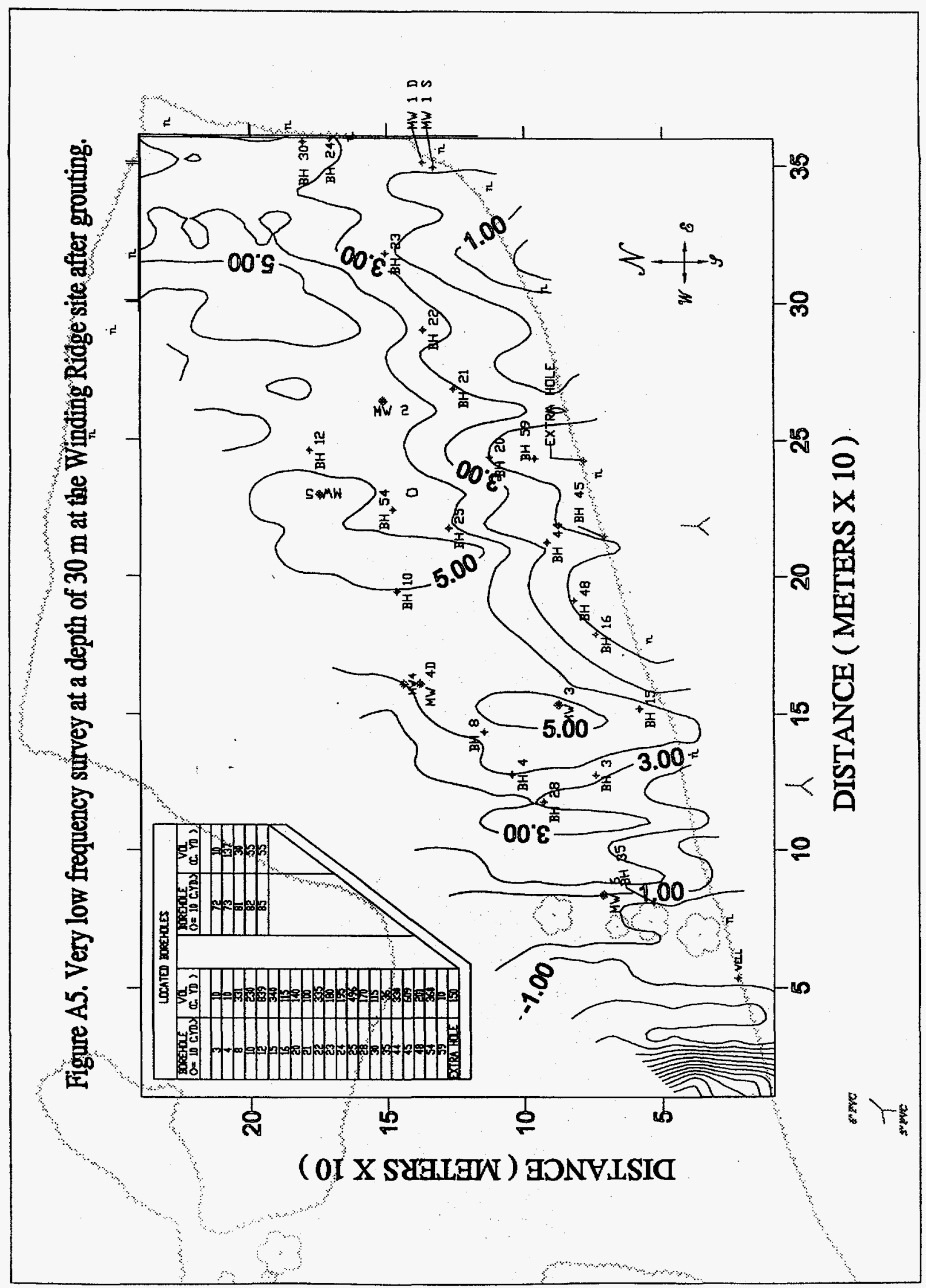




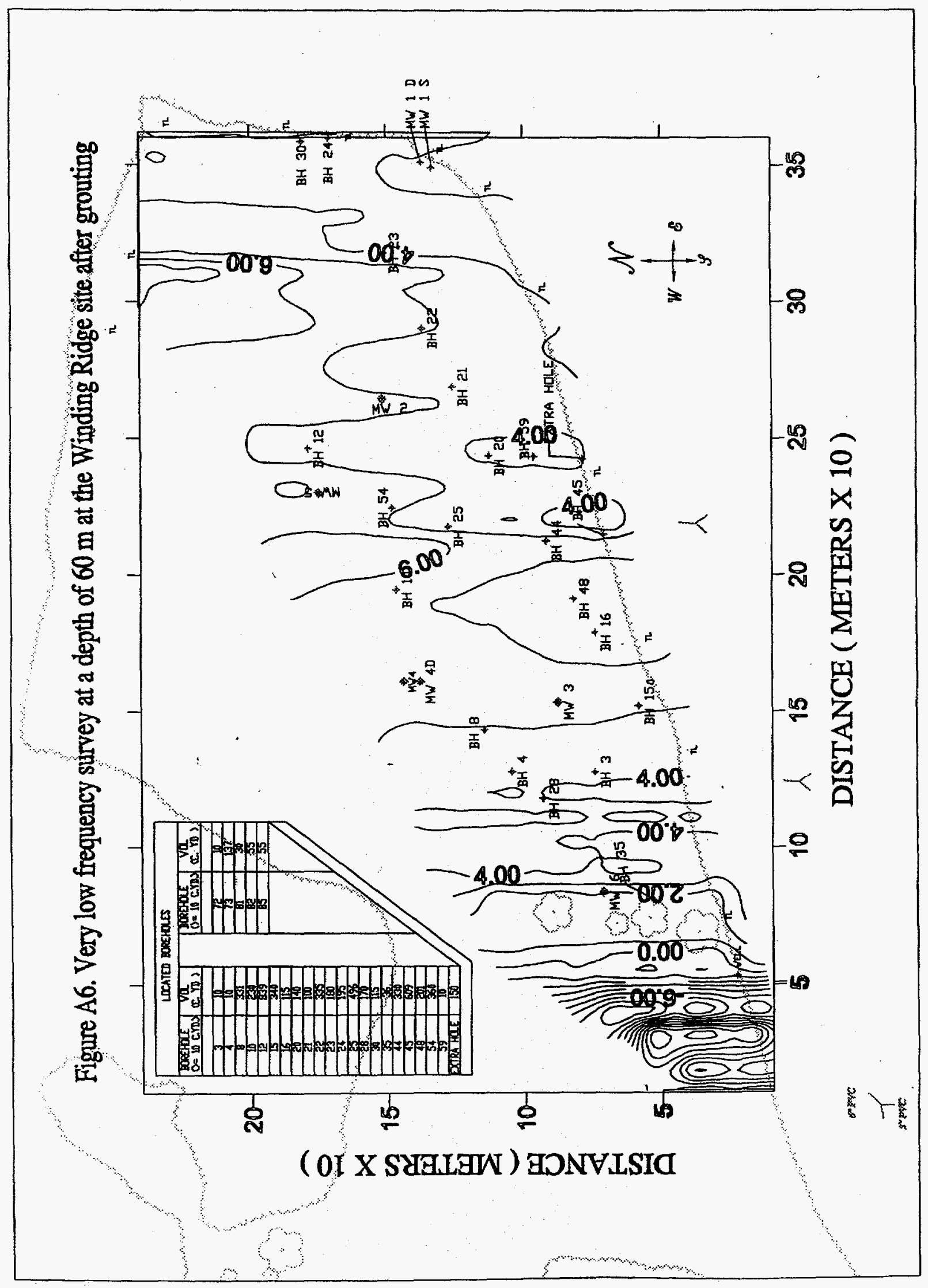




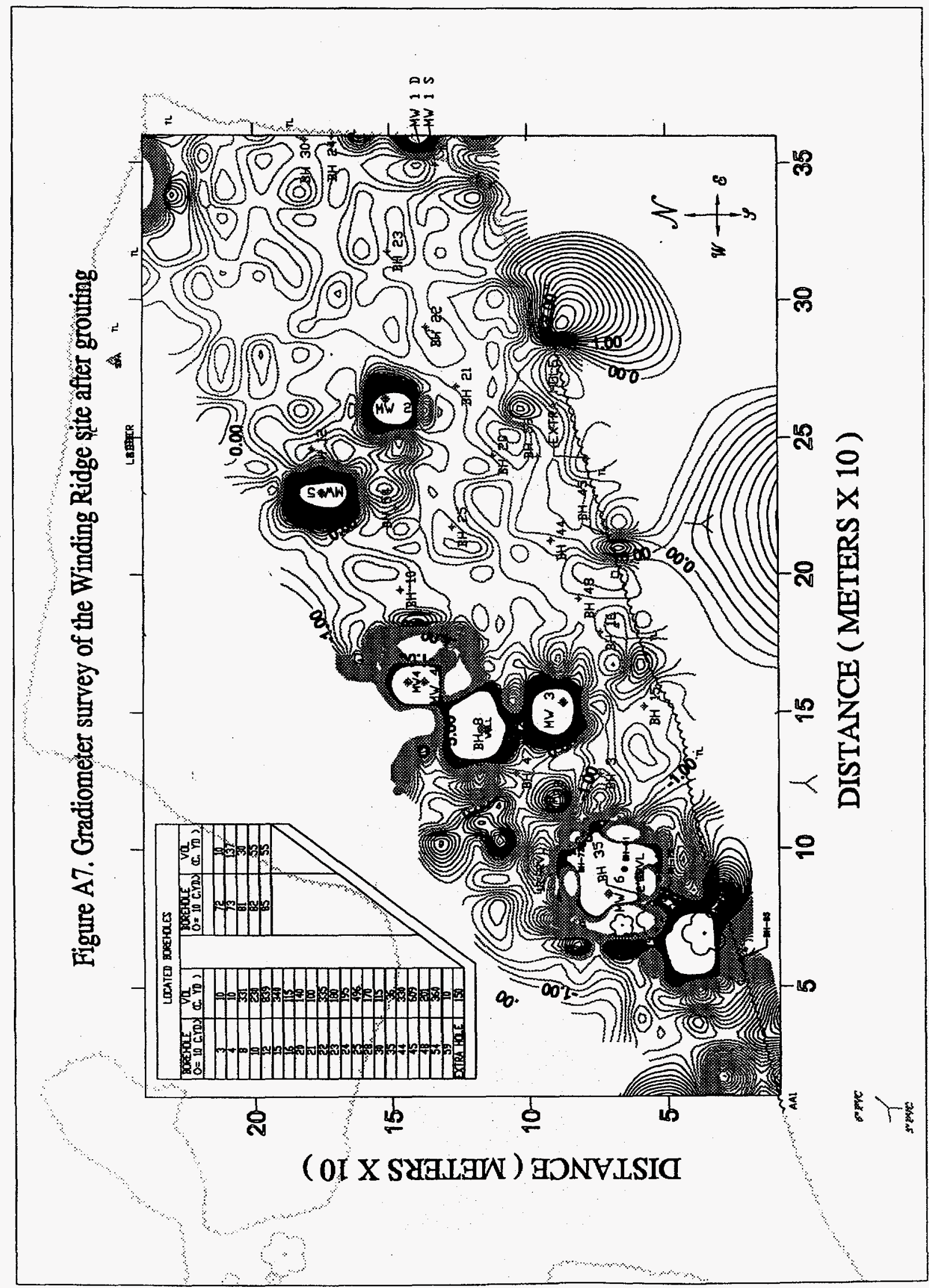

